\title{
Outpatient appointments in private practices in Tehran, Iran
}

\author{
Afsoon Aeenparast ${ }^{1 *}$, Faranak Farzadi ${ }^{1}$, Ali Asghar Haeri-Mehrizi ${ }^{1}$ \\ 1. Health Metrics Research Center, Iranian Institute for Health Sciences Research, ACECR, Iran
}

Received: 1 July 2020

Accepted for publication: 1August 2021

[EPub a head of print-30 August 2021]

Payesh: 2021; 20 (4): 407- 414

\begin{abstract}
Objective(s): outpatient services are an important part of health services. One important aspect of outpatient services is outpatient appointments. The study aimed to investigate the outpatient appointments and time management status in private practices.

Methods: This was a cross-sectional study that was conducted in Tehran in 2020. Two hundred and eight practices were selected by using convenient sampling. Data was collected using a 50-items self-designed questionnaire. The validity and reliability of questionnaires were tested before data collection. SPSS software version 23 was used for data analyses.

Results: More than half of the practices $(56.3 \%)$ were specialists' offices. In $85.6 \%$ of the practices patients were admitted on schedule. Data indicated that in most clinics scheduled patients were in priority for being visited by the physician (59.3\%). Compared to younger physicians, the possibility of not using appointment systems was higher in older physicians and among physicians with higher working experiences $(\mathrm{P}$ value $=0.01$ and $\mathrm{P}$ value $=0.039$ respectively).

Conclusions: In general, the findings showed that the age and work experience of the physicians might play an important role in the use of queuing systems in medical practices. It seems that simplifying the appointment methods can be effective in increasing the use of appointment systems and improving the management of waiting time for outpatients in private practices. It is the responsibility of health system managers and experts to produce simple tools and methods without the need for sophisticated technology for this group of outpatient service providers.
\end{abstract}

Key words: Waiting time, Outpatient, Appointment

\footnotetext{
* Corresponding author: Health Metrics Research Center, Iranian Institute for Health Sciences Research, ACECR, Iran

E-mail: aeenparast.af@gmail.com
} 


\title{
وضعيت نوبت دهى در مطب هاى بزشكى شهر تهران و عوامل موثر بر آن
}

\author{
افسون آيين يرست'، فرانك فرزدى '، على اصغر حائرى مهريزى'
}

ا. مركز تحقيقات سنجش سلامت، يُوهشكده علوم بهداشتى جهاد دانشكاهى، تهران، ايران

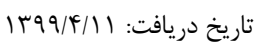

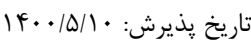

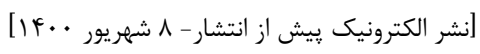

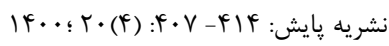

جكيده

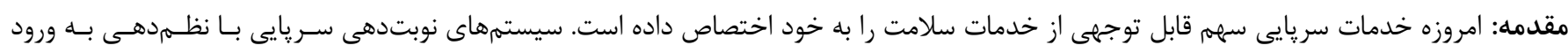

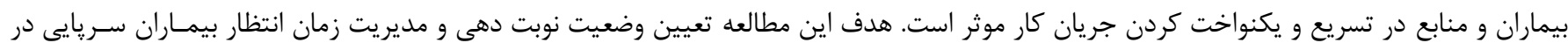
مطب هاى يزشكى شهر تهران بود.

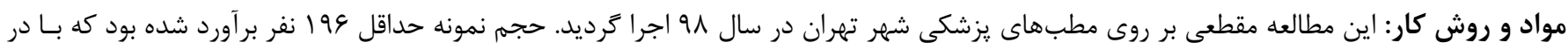

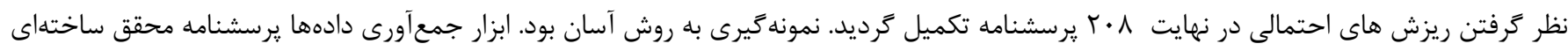

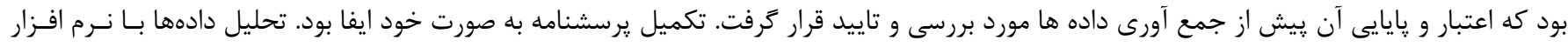
SPSS

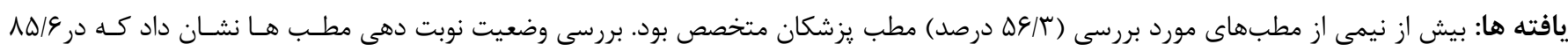

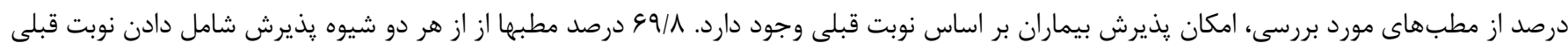

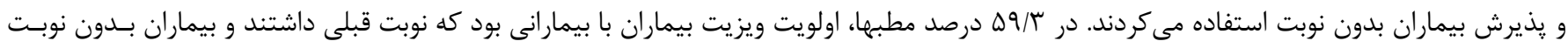

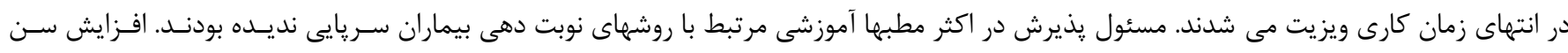

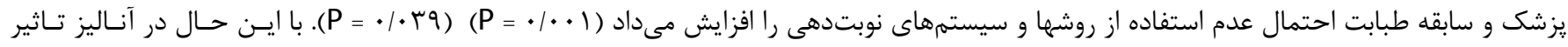

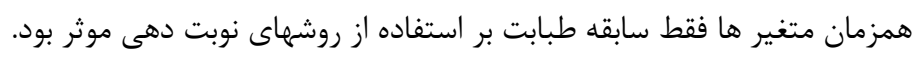

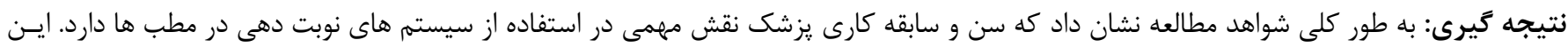

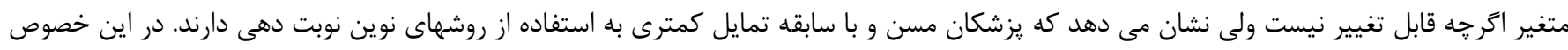

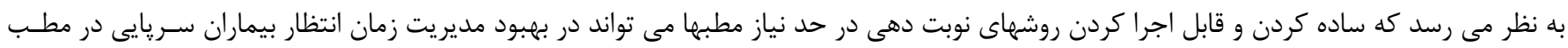

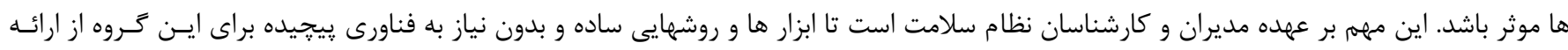

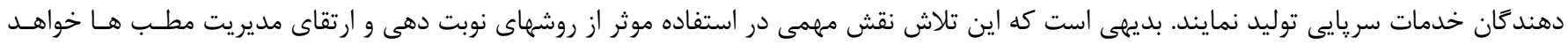

كليدوازه: زمان انتظار، بيمار سريايى، نوبتدهى بيماران

كداخلاق: IR.ACECR.IBCRC.REC.1397.016 
مختلفى با هدف افزايش سطح خدمت دهى به بيمـاران سـريايى بـاــا

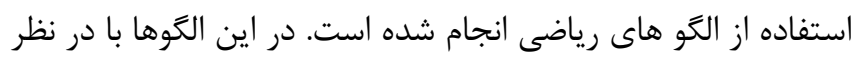

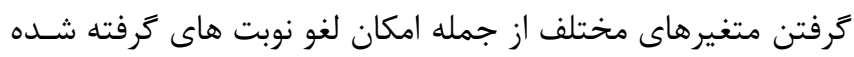

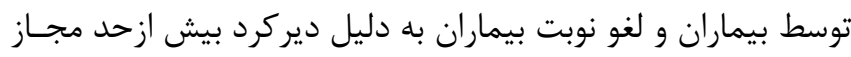

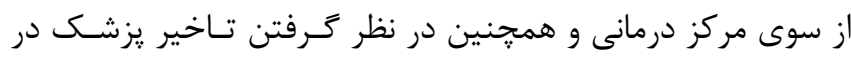

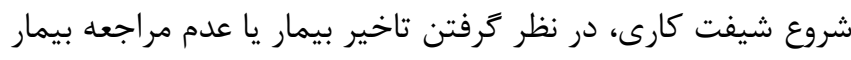

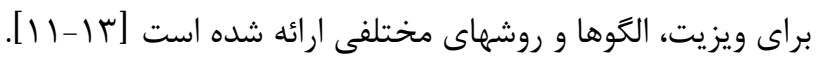

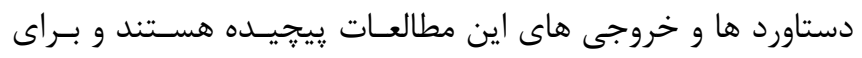

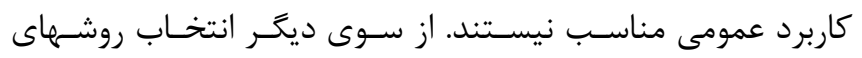

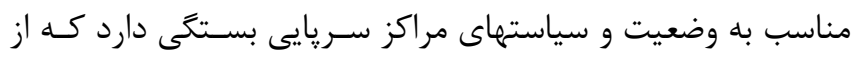
يك مركز به مركز ديخر مى تواند متفاوت باشد. انجام اين مطالعـات

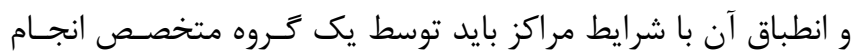

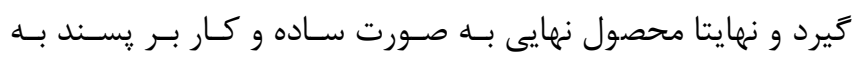

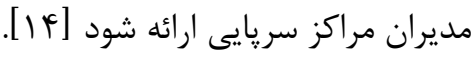

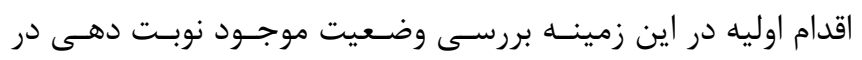

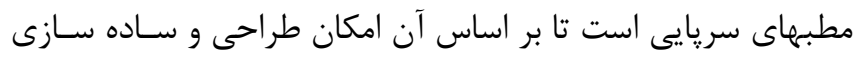

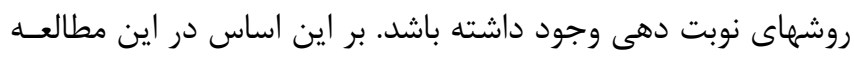
تلاش كرديد اطلاعات زمينه اى در مورد وضـعيت موجـود سيسـتم

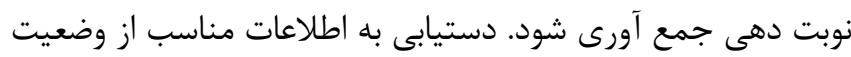

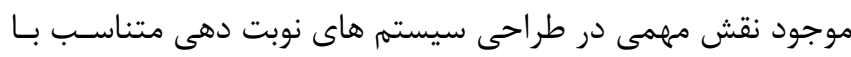
شرايط سيستم هاى ارائه دهنده خدمت دارد.

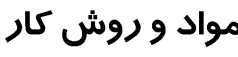

در اين مطالعه مقطعى، جامعه مورد مطالعه مطب هاى شـهر تهـران

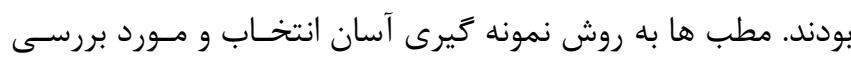

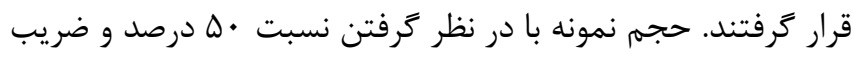

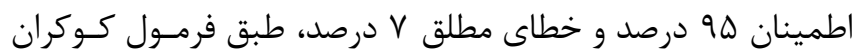
$n=\frac{z_{1-\frac{\alpha}{2}} \mathrm{P}(1-\mathrm{P})}{d^{2}}, \mathrm{p}=5, \mathrm{~d}=0.07, \alpha=0.05$

$$
\text { حدود } 199 \text { نفر برآورد شد. }
$$

با توجه به احتمال ريزش نمونه ها، بيشتر از حداقل محاسـبه شـــه

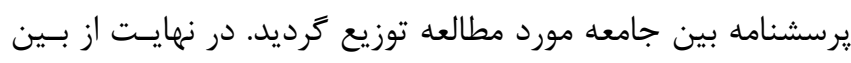

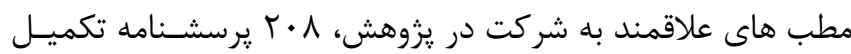

شده جمع آورى گرديد.

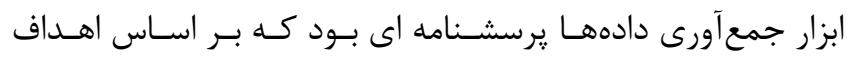

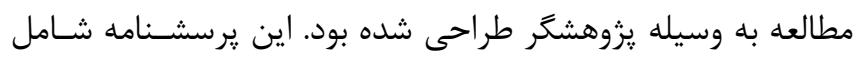

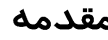

در عصر حاضر خدمات سـلامت حجـم عمــده اى از توليـد ناخـالص

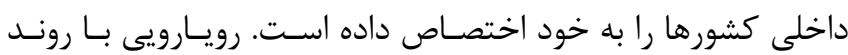

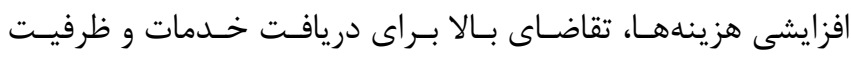

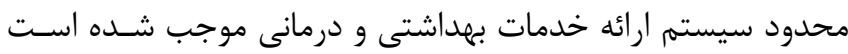

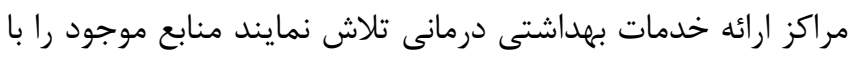

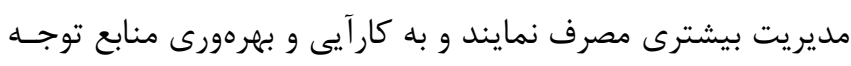

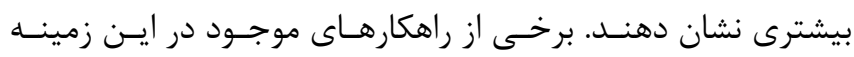

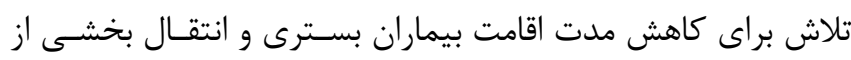

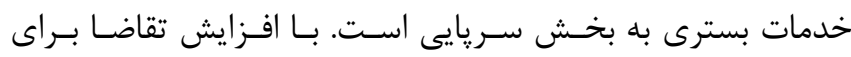

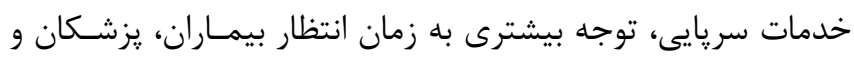

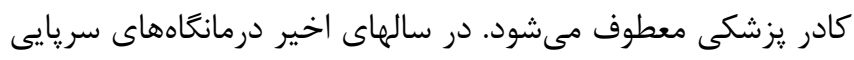

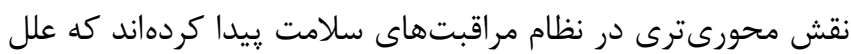

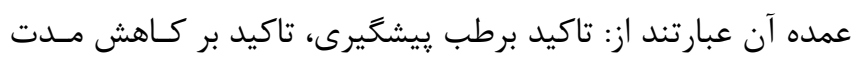

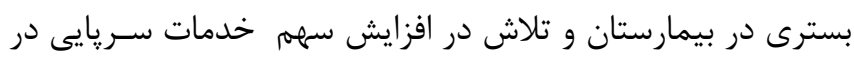

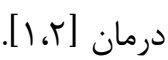

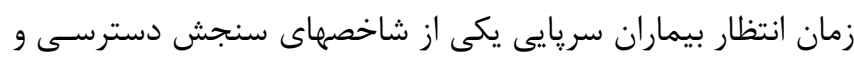

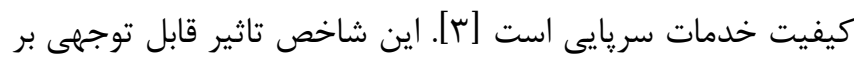

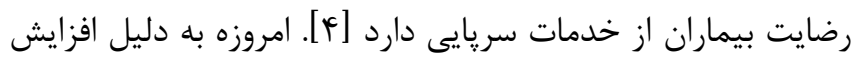

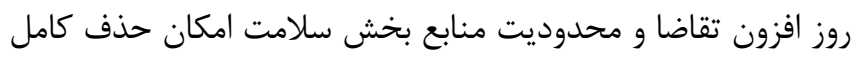

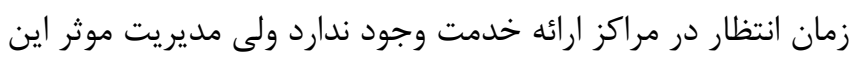

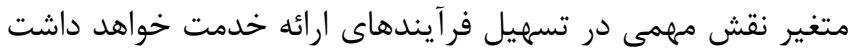

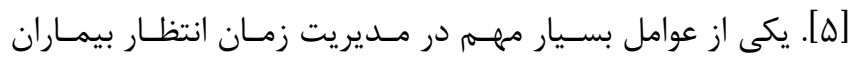

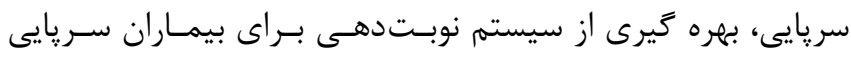

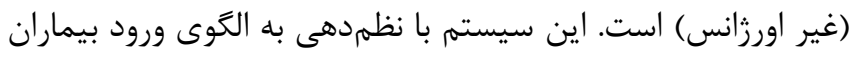

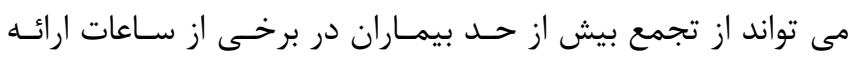

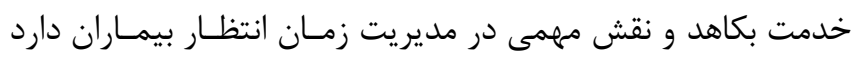
.[द-^]

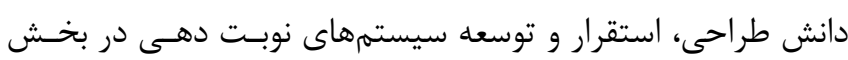

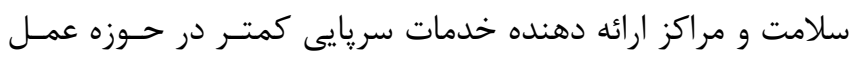

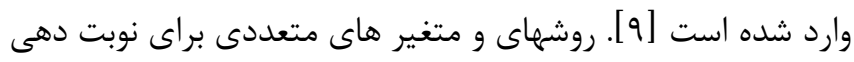

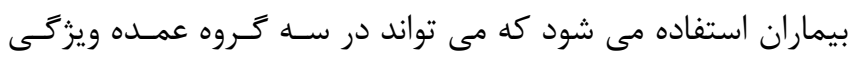

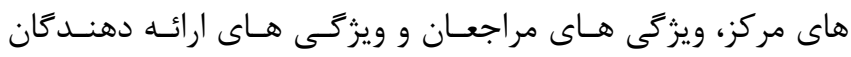

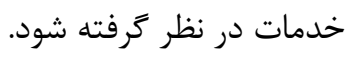

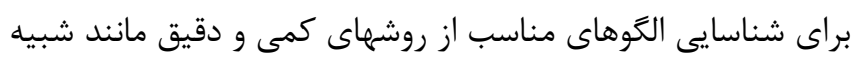

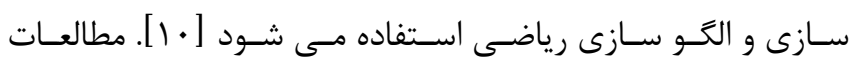


مى دهند منشى مطب به سوالات ياسخ دهد. بر اساس اين بـازخورد و كاهش محدوديت فـوق در صـورت صـلاحديد يزشـكان منتخـب،

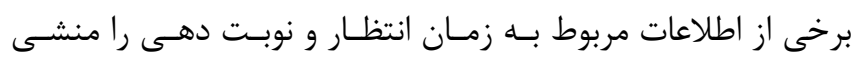

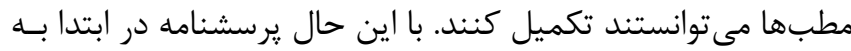

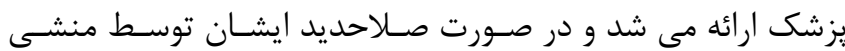
مطب تكميل مى كرديد.

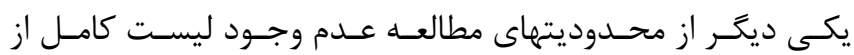

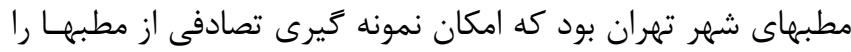

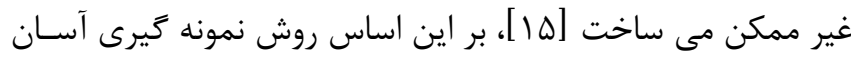

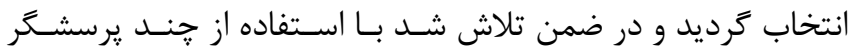
آموزش ديده، مناطق اصلى تهران از نظر استقرار مطب هــا [ها] مراجعه حضورى براى تكميل يرسشنامه ها يوشش داده شود.

\section{يافتهها} بررسى يافته ها نشان داد كه بيشـتر از نيمسى از مطـب هـاى مـورد

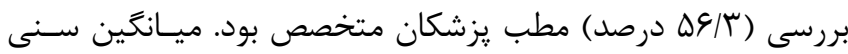

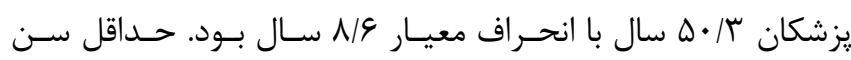

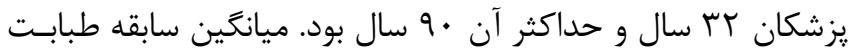

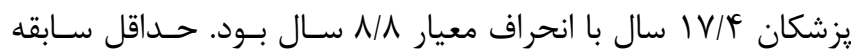

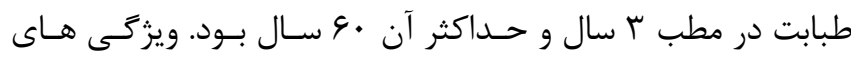

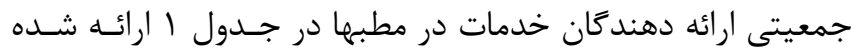
است. به منظور بررسى روشهاى نوبت دهى سوالات مختلفى مطـرح

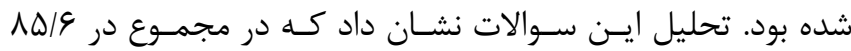

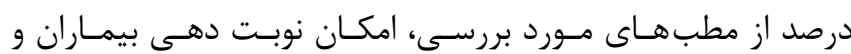
يذيرش بيماران بر اساس نوبـت قبلى وجـود دارد و فقط حسـدود 1

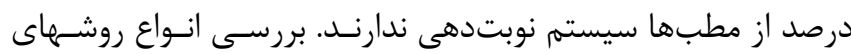

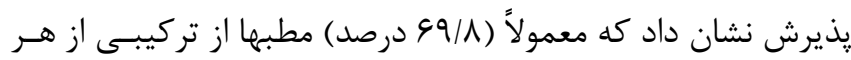

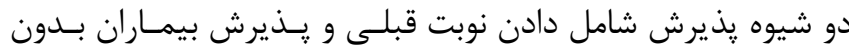

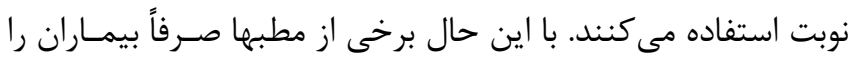

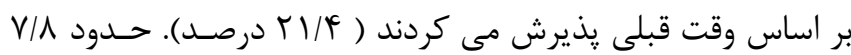

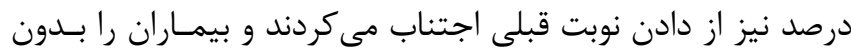

نوبت قبل بر اساس مراجعات روزانه يذيرش مى كردند (جدول Y).

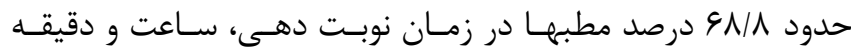

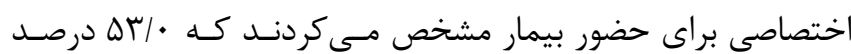

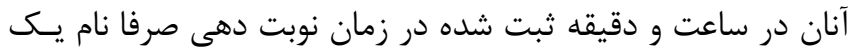

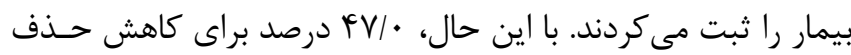

• له گويه بود كه عملكرد مطبهاى يزشكى را در مورد نوبتدهـى و مديريت زمان انتظار بيماران مورد بررسى قرار مى داد داد.

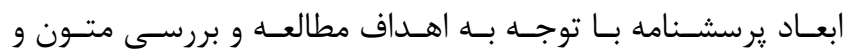

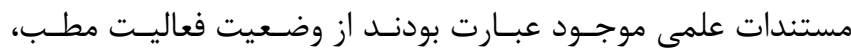
وضعيت نوبت دهى مطب، وقت شناسى بيماران و يزشـك، دانسش و

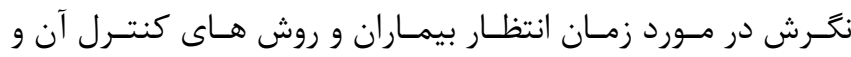

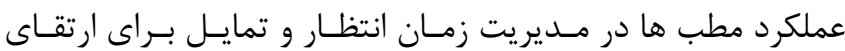
سيستم نوبت دهى مطب بود.

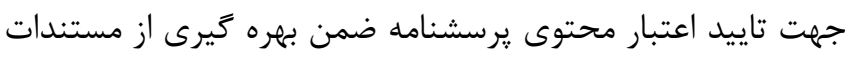

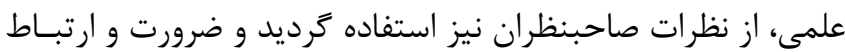

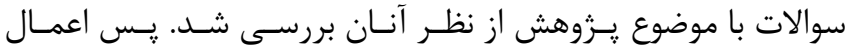

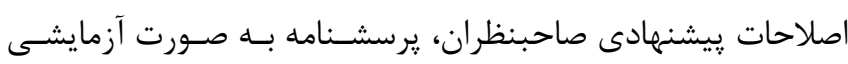

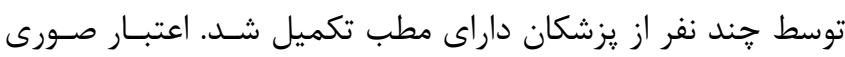

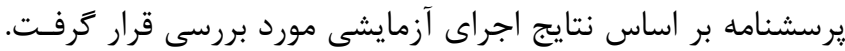

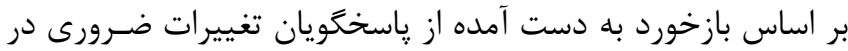

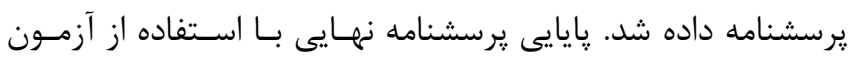

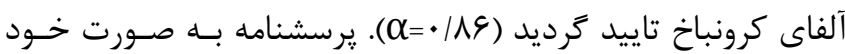
ايفا طراحى شده بود با اين حال يرسشــران حضـور داشـتند تـا در

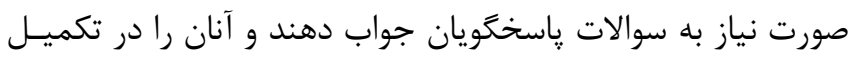
يرسشنامdها يارى كنند. در اين مطالعه براى تحليـل داده هــا از روشهــاى آمـار توصـيفى و تحليلى با بهره گيرى از نسخه سب نرم افزار SPSS استفاده شد.

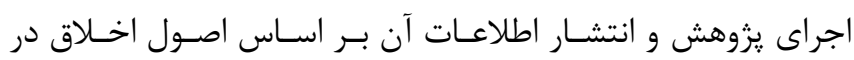

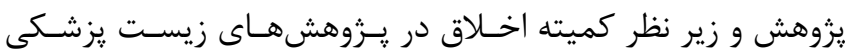

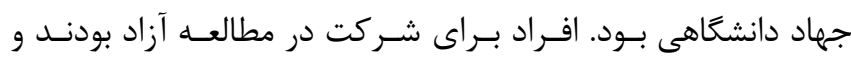

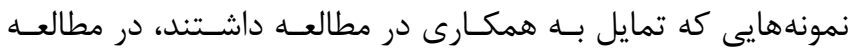

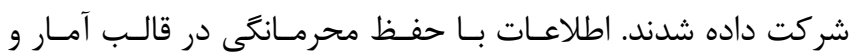
تحليلهاى كلى منتشر شـد و اطلاعـات فـردى نمونـهـ هــاى مـورد مطالعه محرمانه بود. مشغله يزشكان به عنوان يكى از عوامـل مخــدوش كنـــــهـ بـود كـهـ مى توانست موجب كاهش تمايل آنان براى شركت در مطالعـه شـود.

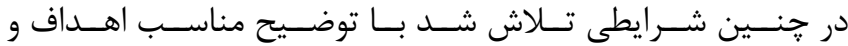

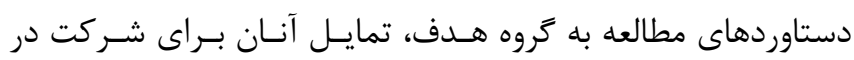

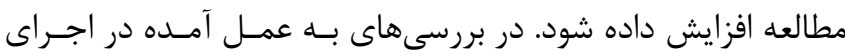

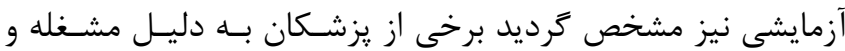

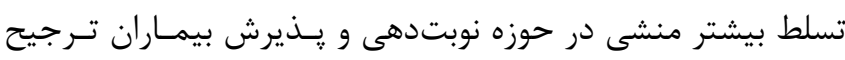


بدون نوبت مابين ساير بيماران ويزيـت مسى شـدند. اولويـت ويزيــت بيماران در جدول ع أرائه شده است.

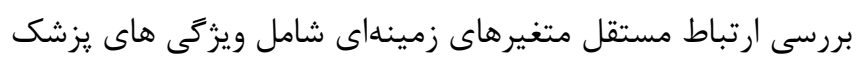

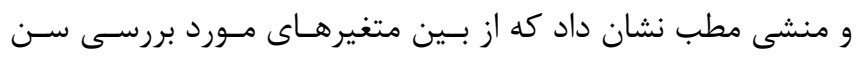

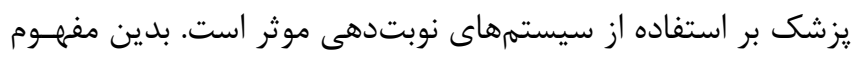

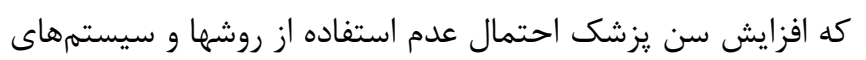

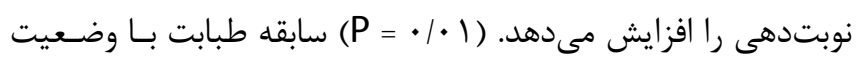

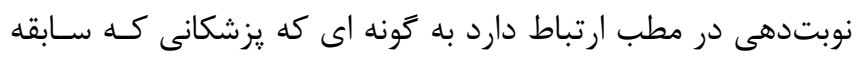

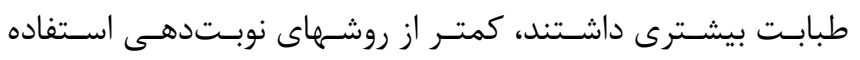

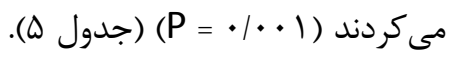

تاثير منفى عدم مراجعه افـراد، در هــــــــازه زمـانى بـهـ جنــد بيمـار

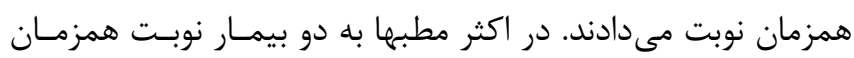

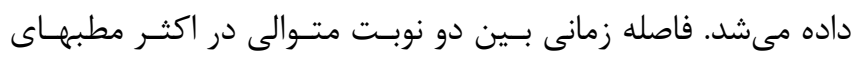

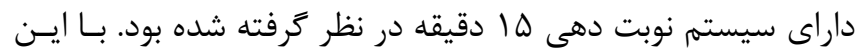
حال در كل مطبها اين شاخص كمتر از ها دقيقه بـود (جـدول ؟ا).

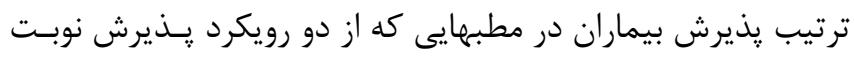

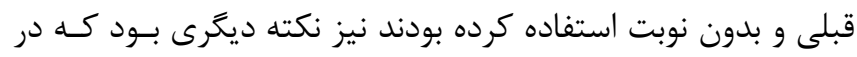

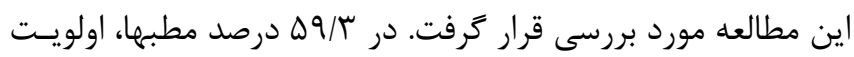

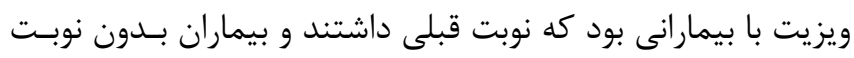

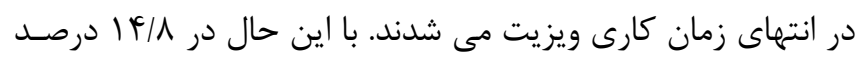
مطبها ضمن اولويت دادن بـهـ بيمـاران داراى وقـت قبلـى بـى بيمـاران

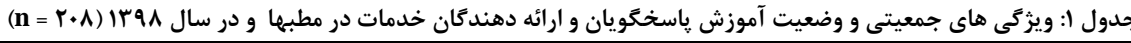

\begin{tabular}{|c|c|c|}
\hline 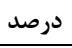 & تعداد & \\
\hline & & فرد هاسخكو \\
\hline$r q / \Lambda$ & $\wedge$. & 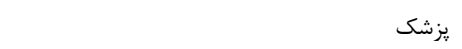 \\
\hline $4 \cdot \pi$ & $|r|$ & 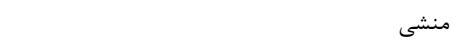 \\
\hline \multirow[t]{2}{*}{ - } & v & بى ياسخ \\
\hline & & جنسيت يزشك \\
\hline $9 \vee / \Delta$ & irv & مرد \\
\hline$r T / Q$ & 99 & 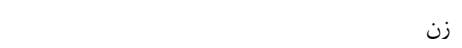 \\
\hline \multirow[t]{2}{*}{ - } & $\Delta$ & بى ياسخ \\
\hline & & تخصص يزشك \\
\hline $1 / / 9$ & rq & 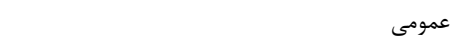 \\
\hline$\Delta \xi / \Gamma$ & 119 & 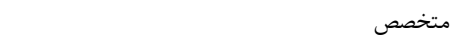 \\
\hline$r F / \Lambda$ & $\Delta 1$ & فوق تخصص \\
\hline \multirow[t]{2}{*}{ - } & r & بى پاسخ \\
\hline & & جنسيت منشى \\
\hline N/9 & 11 & مرد \\
\hline $91 / 1$ & 110 & 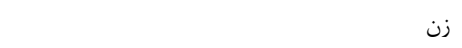 \\
\hline \multirow[t]{2}{*}{ - } & $\Delta$ & بى لِاسخ \\
\hline & & 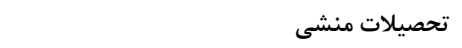 \\
\hline$\%$ & $\wedge$ & 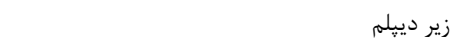 \\
\hline$r \cdot 10$ & 4. & دييلم \\
\hline $9 \% / \Delta$ & ITV & 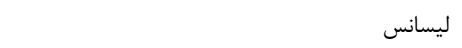 \\
\hline $1 / \cdot$ & r & 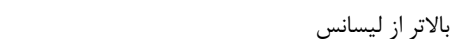 \\
\hline \multirow[t]{2}{*}{ - } & 11 & بى ياسخ \\
\hline & & شركت منشى در دوره هاى تخصص منشى كرى \\
\hline $19 / 0$ & rI & بلى \\
\hline$\Delta T / T$ & $1 .$. & خير \\
\hline$r \cdot / r$ & $\Delta V$ & نمى دانم \\
\hline- & $r$. & بى پاسخ \\
\hline
\end{tabular}




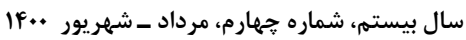

نشريه يروهشكده علوم بهداشتى جهادانشگاهى

جدول r: روش يذيرش مورد استفاده در مطب يزشكان مورد بررسى در شهر تهران در سال

\begin{tabular}{|c|c|c|}
\hline 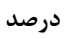 & 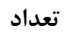 & \\
\hline$r / / F$ & +1 & فقط پذيرش براساس نوبت قبلى \\
\hline $\mathrm{V} / \mathrm{\Lambda}$ & 10 & فقط يذيرش روزانه (بدون نوبت قبلى) \\
\hline $99 / 1$ & IrF & تركيب هر دو روش يذيرش فوق \\
\hline
\end{tabular}

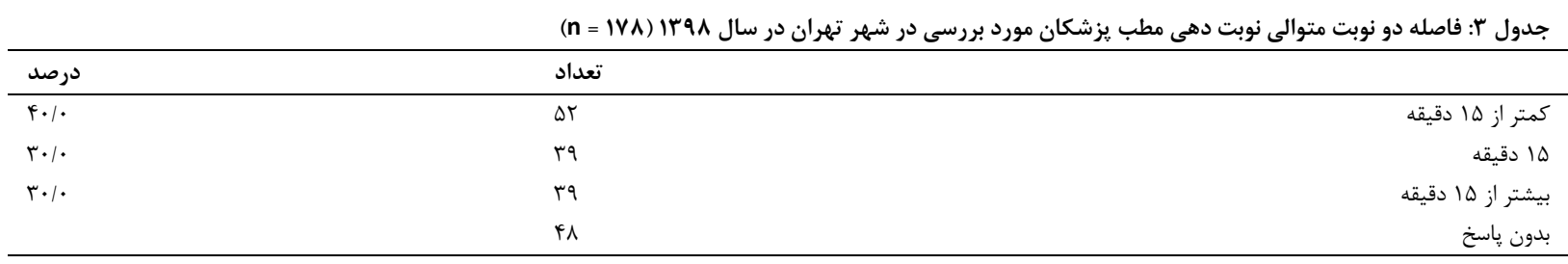

\begin{tabular}{|c|c|c|}
\hline درصد & تعداد & \\
\hline$\Delta 9 / \Gamma$ & at & اولويت با بيماران داراى نوبت و ويزيت بيماران بدون نوبت در پايان ساعت كارى \\
\hline $\mid F / \Lambda$ & 19 & اولويت با بيماران داراى نوبت و ويزيت بيماران بدون نوبت مابين ساير بيماران \\
\hline $1 \% / 9$ & 10 & ويزيت هر دو گروه به ترتيب ورود \\
\hline$\Delta / 4$ & 4 & اولويت براساس شرايط بيمارى و وضعيت جسمى بيمار \\
\hline $9 / 0$ & $\checkmark$ & ساير موارد \\
\hline
\end{tabular}

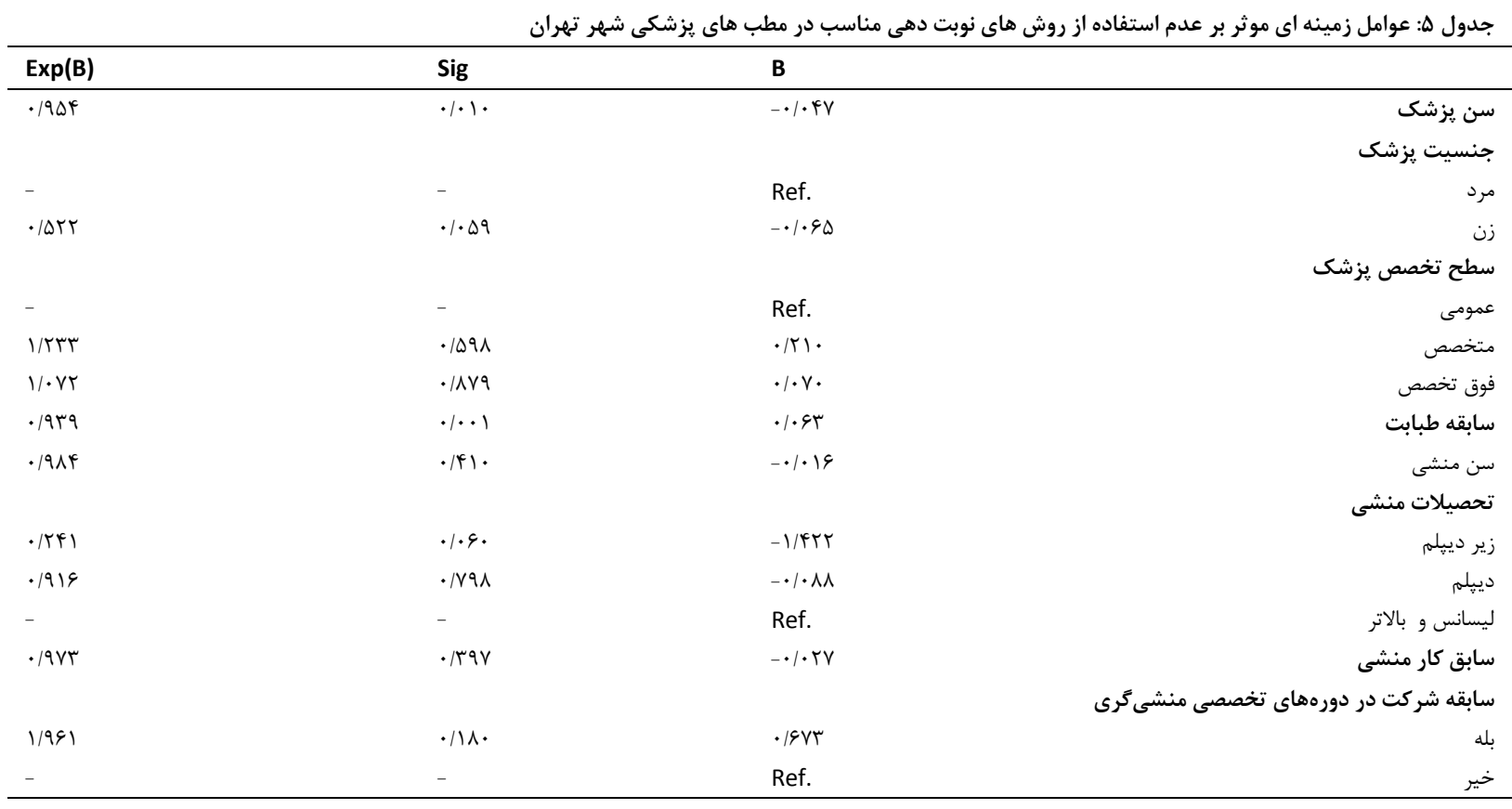

اوليه وجود ندارد. اولين اقدام مىتواند ارتقاء سيسته هاى نوبت دهى دانى

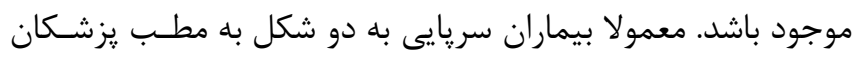

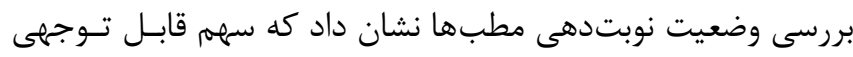

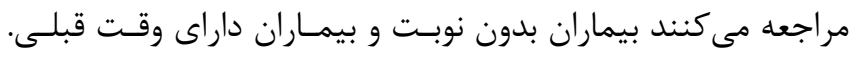

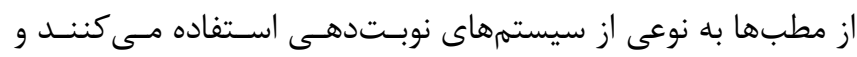

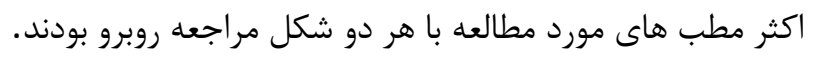

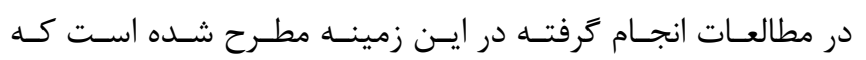
فقط 1 درصد مطب ها به شـكل سـنتى و فقـط براسـاس مراجعـات

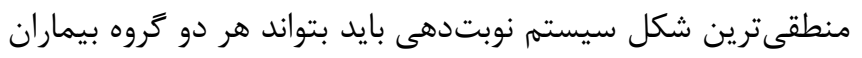

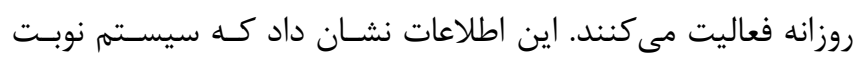

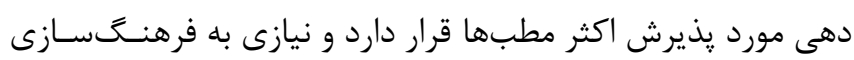


سوى بيماران علاقمند هسـتنـد از روش اول اسـتفاده مسى كننــد تـا

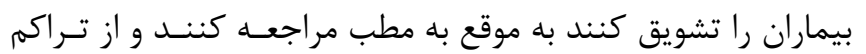

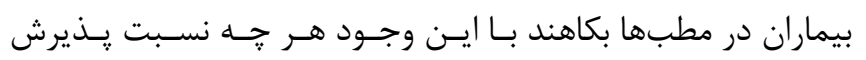

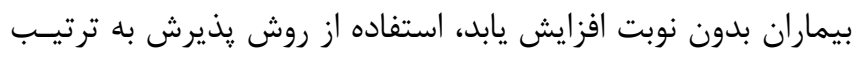

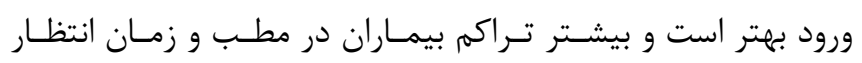
بيماران را كاهش مى بـدهد. نتيجه تحليل تاثير متغير هاى زمينهاى نشان داد كه دو متغير سـن

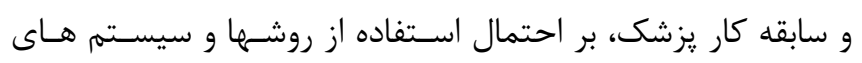

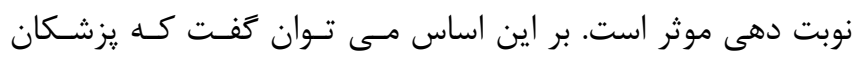

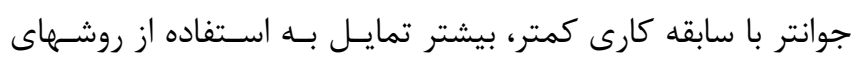

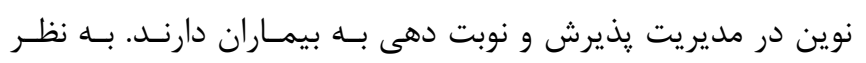

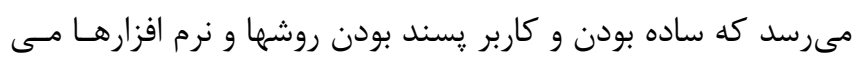

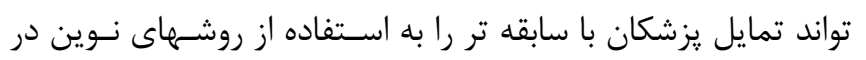

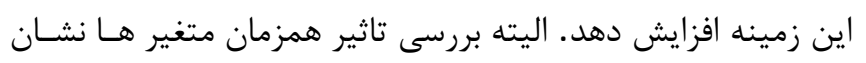

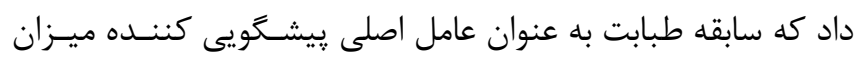

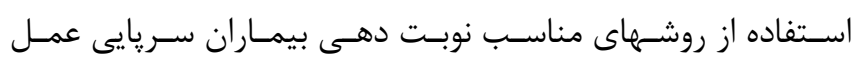

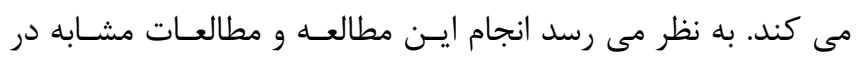

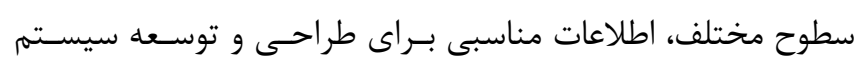
هاى نوبت دهى بيماران سريايى خواهد داشت. اطلاعات منتشر شده

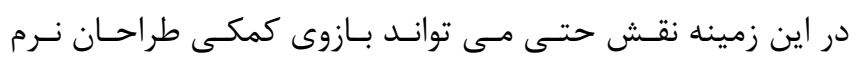

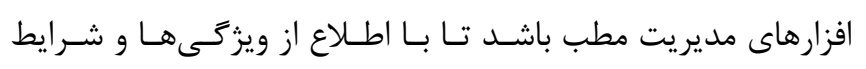

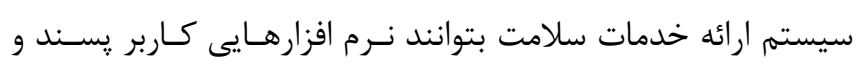
مناسب نياز سيستم سلامت طراحى كنند.

\section{سهم نويسند}

افسون آيين يرست: طراحى و اجراى مطالعه، تدوين مقاله فرانك فرزدى: همكارى در طراحى مطالعه، بازبينى مقاله

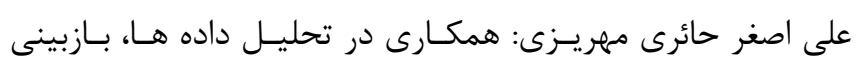
مقاله

\section{منابع}

1. Toufighi H, Sharifi V, Alaghband Rad J, Shadloo B. Development and Implementation of Discharge Planning Service in Roozbeh Hospital. Iranian Journal of Psychiatry and Clinical Psychology 2018; 24:56-69 [In Persian]

2. Shabani H, Rezayatmand R, Mohammadi F. Determinants of Health Expenditures in Iran and Other
را يذيرش كند. البته نسبت يـذيرش هـر دسـته بــه سياسـت ارائـهـ

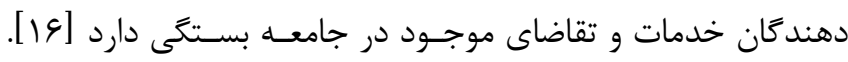

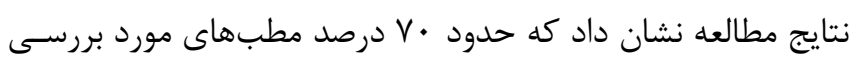
شرايط يذيرش هر دو گروه بيماران را فراهم كرده بودند. با اين حال

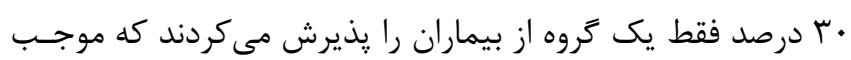

محدوديت دسترسى بيماران به خدمات يزشكى مطب مىشود.

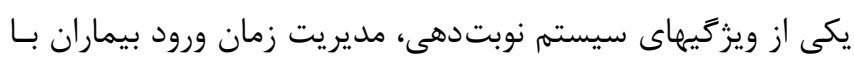

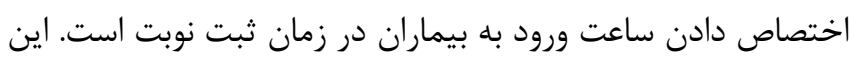

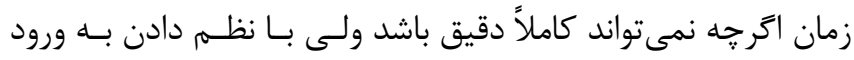

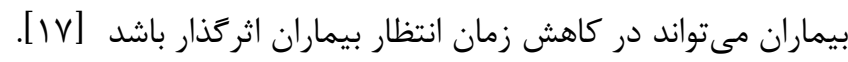

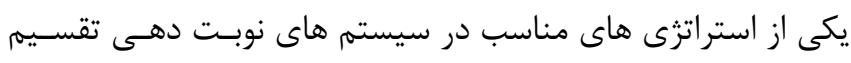

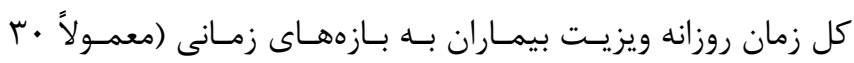

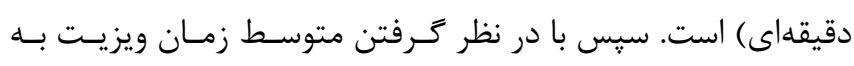

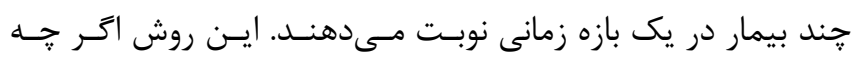

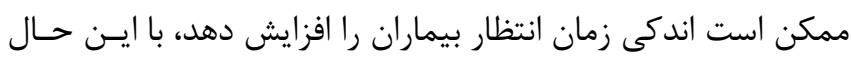

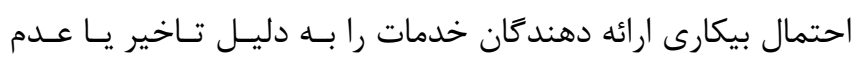

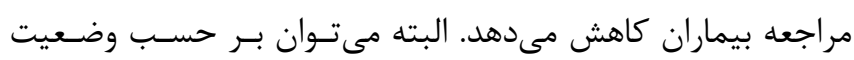

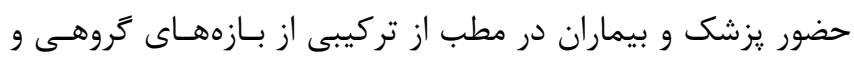

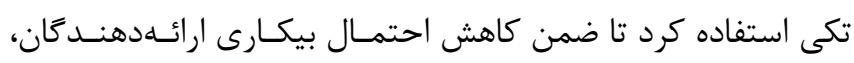

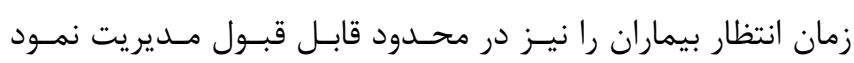

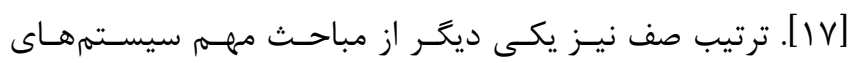
نوبتدهى است.

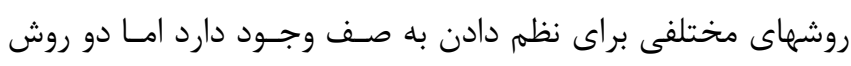

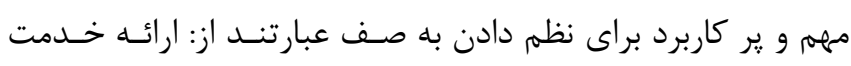

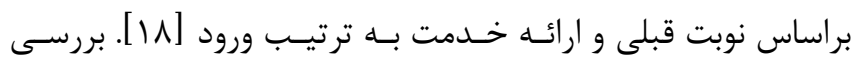
يافتهها نشان داد كه بيشتر مطبها از روش اول استفاده مـى كنــــد.

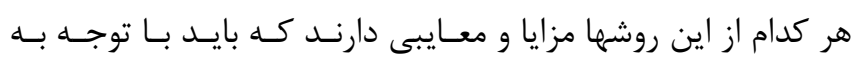

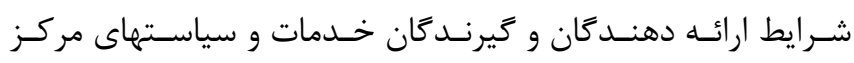
انتخاب شود. عموماً مراكزى كه به دادن نوبت قبلى ونى و رعايـت آنـ آن از

Country Members of Perspective Document of 1404 of Iran. Health Information Management 2019; 16: 1823 [In Persian]

3. Faraji Khiavi F, Qolipour M, Dashtinejad Z, Mirr I. Determination of Dimensions and Items of Outpatient Service Quality for Ahvaz Hospitals. payavard Salamat 2018; 11:490-500 [In Persian] 
4. Faraji Khiavi F, Qolipour M, Dashtinejad Z, Mir I. Relationship between outpatients' examination time and perceived service quality in teaching hospitals of Ahvaz: 2015. Rahavard Salamat Journal 2017; 3:24-35 [In Persian]

5. Aeenparast A, kheirandish M, Maftoon F, Farzadi F. Identifying key variables for designing a scheduling system for outpatient appointments: A systematic review. Payesh 2017; 16:735-745 [In Persian]

6. Begen MA, Levi R, Queyranne M. Technical Note-A Sampling-Based Approach to Appointment Scheduling. Operations Research 2012; 60: 675-681

7. Creemers S, Beliën J, Lambrecht M. The optimal allocation of server time slots over different classes of patients. European Journal of Operational Research 2012; 219: 508-521

8. Koeleman PM, Koole GM. Optimal outpatient appointment scheduling with emergency arrivals and general service times. IIE Transactions on Healthcare Systems Engineering 2012; 2: 14-30

9. Cayirli T, Gunes ED. Outpatient appointment scheduling in presence of seasonal walk-ins. Journal of the Operational Research Society 2014; 65: 512-531

10. Liang B, Turkcan A. Acuity-based nurse assignment and patient scheduling in oncology clinics. Health Care Management Science 2016 ;19: 207-26

11. Wang J, Fung RJ. Dynamic appointment scheduling with patient preferences and choices. Industrial Management \& Data Systems 2015; 115: 700-717
12. Heshmat M, Eltawil A. Comparison between outpatient appointment scheduling and chemotherapy outpatient appointment scheduling. The Egyptian International Journal of Engineering Sciences \& Technology $2016 ; 19: 326-32$

13. Chen $\mathrm{Y}$, Kuo $\mathrm{YH}$, Fan $\mathrm{P}$, Balasubramanian $\mathrm{H}$. Appointment overbooking with different time slot structures. Computers \& Industrial Engineering 2018; 124:237-48

14. Zacharias C, Yunes T. Multi-modularity in the stochastic appointment-scheduling problem with discrete arrival epochs. Management Science 2020; 66:744-63

15. Aeenparast A, Farzadi F, Maftoon F. Waiting time for specialist consultation in Tehran. Archives of Iranian Medicine (AIM) 2012;15: 756-8

16. Munavalli JR, Rao SV, Srinivasan A, van Merode GG. Integral patient scheduling in outpatient clinics under demand uncertainty to minimize patient waiting times. Health informatics Journal 2019 26: 435-448

17. Barghash M, Saleet H. Enhancing outpatient appointment scheduling system performance when patient no-show percent and lateness rates are high. International Journal of Health Care Quality Assurance 2018; 31: 309-326

18. Thombare M, Sukhwani R, Shah $P$, Chaudhari $S$, Raundale P. Efficient implementation of multilevel feedback queue scheduling. International Conference on Wireless Communications, Signal Processing and Networking (WiSPNET) 2016; 23:1950-1954 